\title{
Safety planning for technology: displaced women and girls' interactions with information and communication technology in Lebanon and harm reduction considerations for humanitarian settings
}

\author{
Kristy Crabtree ${ }^{1,3^{*}}$ id and Petronille Geara ${ }^{2}$
}

\begin{abstract}
The appropriate use of mobile technology for service provision, information dissemination, empowerment activities, and data collection in humanitarian settings can have several benefits on both the micro and macro levels for women and girls. Strengthened self-esteem, access to information to support their decision-making, and broadly, gender equality by leveling access between men and women are all benefits. For service providers, technology can extend reach and expand access opportunities. However, these advantages need to be reconciled with two critical challenges: (1) the unique barriers for women and girls to access and utilize technology and (2) the risks that technology might increase harm or gender-based violence, even if unintentionally. The use of technology in humanitarian settings has a gendered imbalance, meaning women and girls face more obstacles than men due to their gender. For women and girls, access and usage are negatively influenced by socioeconomic and cultural barriers. This includes both individual and ecosystem factors including prohibitive cost of devices, attitudes toward women and girls' use of phones and the Internet, issues of security and harassment, and technical literacy and confidence. Though the current humanitarian environment beckons further exploitation of mobile technology for the benefit of women and girls, caution is needed. With an estimated $35 \%$ of women worldwide experiencing physical or sexual violence at some point in their lives, safety is a crucial component to consider in how women and girls can utilize information and communications technology and how humanitarian service providers should be responsible for their access to technology. The threat of genderbased violence impacts how women interact with technology. Service providers need to plan for safety first. Any consideration of information and communications technology introduction should include an understanding of the globally common and locally unique barriers to access and usage, necessary service precautions before implementation, and key opportunities to increase safety measures. The latter includes specific beneficiary messaging, mobile data collection procedures, and planned safety measures for shared or borrowed devices among other recommendations. This article aims to provide practical recommendations for service providers on how to safely introduce information and communications technology into programming for women and girls.
\end{abstract}

Keywords: Technology, Women and girls, Information and communications technology, Safe technology, Mobile devices, Gender-based violence

\footnotetext{
* Correspondence: kristy.crabtree@rescue.org

${ }^{1}$ International Rescue Committee, 122 E. 42nd Street, New York, NY 10186,

USA

${ }^{3}$ Seattle, USA

Full list of author information is available at the end of the article
} 


\section{Background}

Information and communications technologies (ICTs) are used in developing countries and humanitarian settings for economic empowerment, health management, improving access to education, reporting safety risks, agricultural development, and emergency assessments, among other uses. These tools can be understood as the technologies that facilitate access to information, including the Internet, mobile phones or devices, and other communication methods.

In supporting quality programming, ICTs can extend the reach and expand access opportunities for service providers to support beneficiaries. They can be used in different modalities: for registration, monitoring and evaluation, access to information, communication, feedback loops, assessments, and evaluations and to increase the flow of information in service coordination.

Convenient, scalable, and relatively low cost to produce and maintain, ICT tools are also responsive to globally improving wireless networks, which keep them adaptable. An enabling vehicle, ICTs allow service providers to reach beneficiaries in displaced settings, where movement is restricted, and where privacy is prized. In both development and humanitarian settings, ICTs are promoted organizationally and by donors as an innovative way to support service interventions to reach vulnerable populations such as women and girls.

Mobile technology has the potential to facilitate service provision, information dissemination, empowerment activities, awareness raising, and data collection in humanitarian settings, much like development contexts. For the individuals interacting with this technology, the benefits go further as follows: empowerment, increased ability to make informed decisions, strengthened social networks, enhanced income-earning potential, and contributions toward gender equality.

An enabling environment exists to exploit the use of mobile technology for the benefit of women and girls, and many organizations have the capacity to introduce this asset in programming models. Yet, the humanitarian community lacks violence-contextualized recommendations and planning considerations for the safe use of technology in humanitarian settings with women and girls.

In Lebanon in 2017, of the acts of gender-based violence reported to service providers, 93\% were reported by women and girls. These reports come from the women and girls who sought help despite the risks involved. ${ }^{1}$ Of survivors that reported violence, $71 \%$ of the violence was perpetrated by an intimate partner, family member, or caregivers. The impact of gender and the risk of violence need to be considered in humanitarian interventions, including those that involve technology. Protection against these risks should be mainstreamed into considerations about the inclusion of technology to follow the principle of do no harm. In addition, this should include an understanding of the gendered barriers to use.

\section{Methods}

In addition to a lack of research on female ICT use in displacement and crisis settings, there is also an absence of contextualized standards for the introduction of ICTs with women and girls. Therefore, the ability to employ new technology in a safe manner that considers the needs and opinions of women and girls and the risks they face is hampered. To address these gaps, a survey was conducted in Lebanon to identify factors that influence women and girls' access to and use of mobile technology, challenges and potential risks in use, and areas of opportunities (relevance and feasibility).

This descriptive survey aimed to determine the experience of women and girls in terms of access to, barriers, and intended uses of phones or the Internet to inform future implementations of ICTs in humanitarian programming. The overarching research question is what are women and girls' access to mobile phones and the Internet, what are the barriers to their access (real and perceived), and what are their desired uses and safety concerns? In working with potentially vulnerable populations such as forcibly displaced women and girls, is mobile technology the appropriate channel for communication, service provision, information dissemination, awareness raising, and empowerment activities?

Women and girls (displaced populations), aged 15-50, were the target population for this study. Enumerators, all trained female caseworkers, gained access to the subjects by approaching women and girls who were already accessing women and girls' community centers (static safe spaces) and mobile safe spaces from the International Rescue Committee, ABAAD, Danish Refugee Council, INTERSOS, or Caritas. These women's centers offer a variety of services: counseling for incidents of gender-based violence (GBV), GBV risk assessment and response activities, community mobilization, focused psychosocial support (PSS) including dedicated life skills curriculums for women and girls, and non-focused PSS including recreational activities and literacy sessions.

There was no formal recruitment for the study. Informal recruitment of subjects in women's centers allowed the researchers access to a safe environment with easily available services and privacy for survey responses. Since a subject of this survey assessed real and perceived safety risks, a safe and confidential setting was prioritized for the surveying environment per the WHO ethical and safety recommendations for researching, documenting, and monitoring sexual violence in emergencies (World Health Organization 2007). The respondents selected for the survey were not randomized, but biased toward women and girls who accessed services from a non-governmental 
organization in Beirut, Mount Lebanon, South, Tripoli, Akkar, or Bekaa. The results may reflect respondents with an existing help-seeking behavior. International Rescue Committee Institutional Review Board approval was obtained in March 2017.

Convenience sampling was the selected technique for the survey, with a goal of 200 respondents: at least 60 from each targeted demographic age group: 15-19, 2035 , and $35+$. This study specifically targeted adolescent girls as they are a core population for service provision. Dedicated women and girls' community center activities were provided to adolescent girls, so conducting surveys with this group along with adult women allowed the researchers to understand their specific perception.

In conducting the survey, the enumerators asked for women and girls' willingness to participate in the survey. Respondents' consent was ensured, though no names or other identifying information were collected. Staff wrote responses on paper forms or directly into tablets for data entry. Paper forms were then transported in a sealed file to the International Rescue Committee's Lebanon office for data entry. After the files were entered online, the forms were stored in a locked filing cabinet until analysis was complete and then were shredded.

\section{Measures}

\section{Demographic information}

From May to June 2017, the International Rescue Committee, ABAAD, Danish Refugee Council, INTERSOS, and Caritas surveyed 257 women and girls in Lebanon to assess and better understand issues of access, risk, and opportunity in their use of ICTs.

Respondents were categorized in age groups with $2 \%$ for ages $10-14,16 \%$ for ages $15-17,14 \%$ for ages $18-24,56 \%$ for ages $25-45$, and $12 \%$ for ages 46 and older. Of the respondents, the civil/marital statuses were dispersed: $58 \%$ were married; $2 \%$ married, but not recognized in Lebanon; $4 \%$ separated; $5 \%$ divorced; and $26 \%$ single. A significant majority (75\%) were from the displaced Syrian population, followed by respondents from Lebanon (21\%) and the remaining from Palestine or another country (Figs. 1, 2, 3 and 4).

\section{Survey questions}

Beyond demographics, respondents were asked 27 questions regarding the general population's usage of information and communications technology, their personal usage, their individual level of access, and access to information and phones. These included questions such as the following: do people in your community use mobile phones; do women and girls in your community use mobile phones; what do people think about

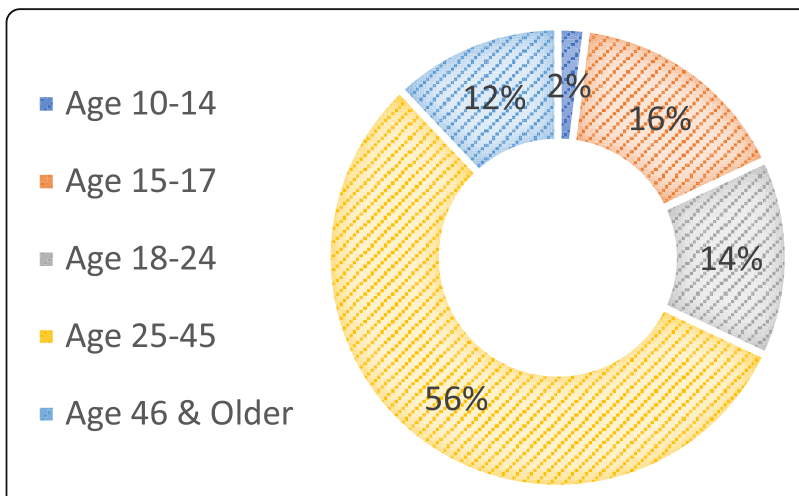

Fig. 1 Respondent age group

women/girls having and using phones and the Internet; is the phone yours, shared, or borrowed; what functions do you use most often; does anyone decide what you do with the phone; how does your family feel about your current use of the Internet; how would you rank the barriers women and girls face in using phones, smart phones, and the Internet; and are there any ways that access to phones/the Internet improves women and girls' safety or meets other needs, among other questions.

\section{Results and discussion}

\section{Usage of and access to information and communication} technology

To start, this survey examined displaced women and girls' ICT usage and access barriers. Understanding the current use of ICTs by women and girls in humanitarian settings will help program decision-makers determine appropriate use of ICTs, possible barriers, and potential opportunities.

The findings show how highly utilized mobile phones are in the community, perceived by respondents at $95 \%$. However, the usage rate drops for women and girls to $88 \%$. When the results are disaggregated by age group, the rates of usage decrease further according to the age of women and girls. Adolescent girls (aged 15-17) had the lowest rates of use, nearly half of the perceived

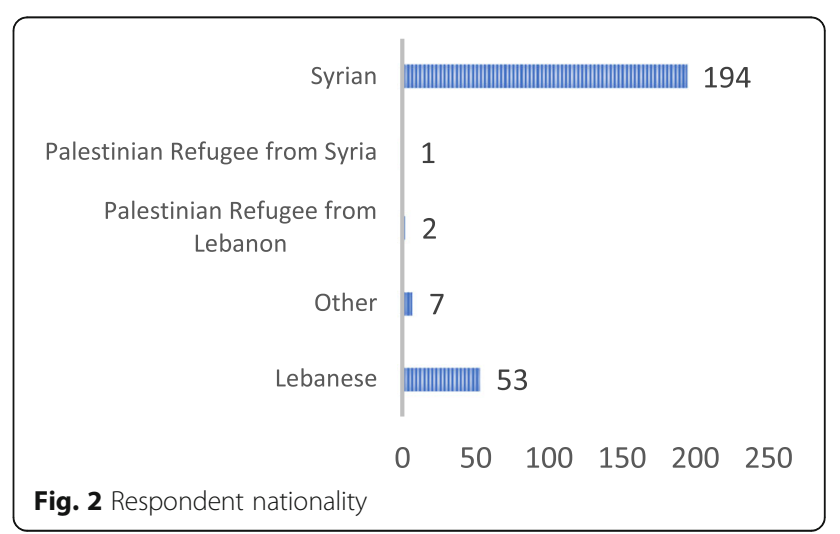




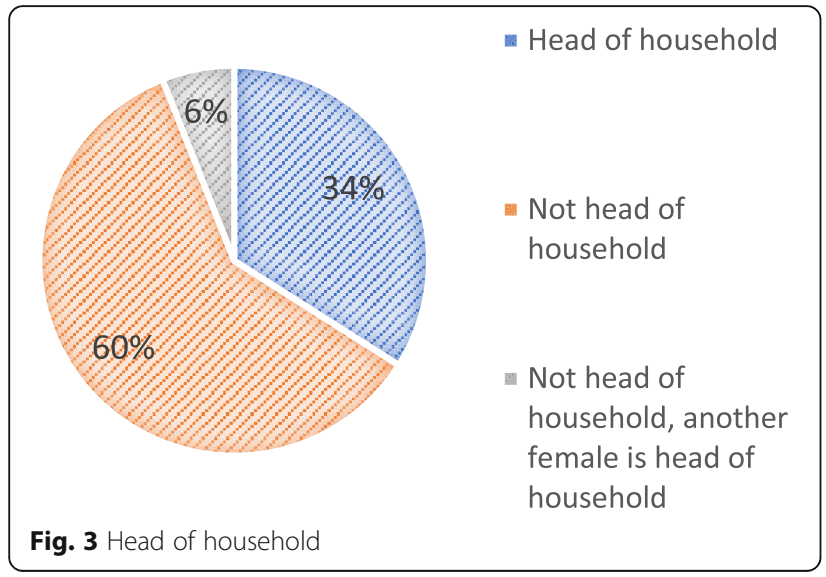

general population rate at $55 \%$. For the age groups $18-$ 24 and 25-45, the numbers increase as compared to adolescent girls but never equal to the rate of general population use. Women and girls' rates of personal mobile phone use (at 77\%) are slightly higher than those of smart phones (at 74\%) and $3 G$ access (at 62\%).

Possession follows a similar trend. Only a third of female respondents reported device ownership. Most women and girls borrow or share devices with intimate partners, parents, or in-laws. Shared is understood as daily access or partial ownership. Borrowed is interpreted as access when needed, but not daily. Adolescent girls (aged 15-17) report only $17 \%$ of device ownership, while females aged 18-24 report $53 \%$ of phone ownership. For adolescent girls, device sharing was exclusive with parents or caregivers. For the $25 \%$ of women aged $18-24$ that shared phones, intimate partners were $56 \%$ and parents $44 \%$.

Overall, according to respondents, there is a reasonable expectation of daily phone use, even for devices that are shared or borrowed. However, sharing or borrowing devices restricts the full benefits of phone usage and affects the freedom of women and girls in choosing and making decisions on their phone usage. Users who share or borrow devices have weaker technical literacy and confidence and cannot access all the benefits of devices, including life-saving services (Santosham 2015).

WhatsApp or other texting platforms were the highest utilized by the respondents followed by calls (primarily

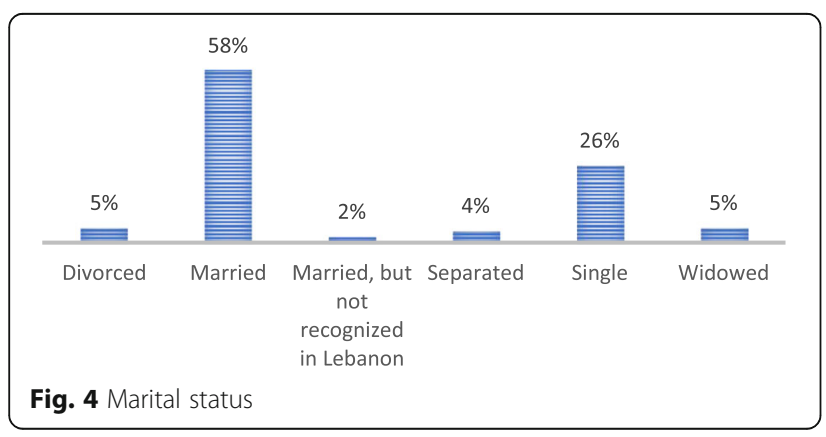

made through WhatsApp or Skype), SMS, games, and news sites or other applications. There were not significant differences between age groups on functions most frequently utilized. Device function preference trends toward communication platforms. Similarly, for respondents that reported a desire for increased phone access and use, the primary goal was increased communication with family and friends.

Credit and the ability to charge devices are critical tasks for the full use of mobile phones. The ability to replenish credit or battery matched the gendered use of phones. Less than half of respondents reported selfpurchase of credit. A majority must share credit, ask for credit, or obtain credit through other means. A majority were also not able to easily charge their devices. Thirtyeight percent of adolescent respondents reported the ability to charge their phone easily. This number rises slightly to $47 \%$ for respondents aged 18-24.

Gendered ICT access and usage have negative effects for females. Women and girls are missing opportunities to contribute from the individual and household to the macro level through their exclusion from mobile technology. Their absence means women lack access to tools, resources, and opportunities to collaborate on key development goals, which has an impact beyond the household and extends to the broader economy (Intel 2012).

Beyond imbalanced device acquisition, this encompasses access to information as well. The condition of instability in accessing news and personal information, called information precarity, can result in increased exposure to violence because personal access to information throughout stages of displacement is "insecure, unstable, and undependable, leading to potential threats to... well-being" (Wall et al. 2015).

\section{Barriers to information and communication technology usage and access}

Respondents perceived the barriers to use of mobile phones by the general population in order of significance as credit acquisition, then device possession. The survey shows the frequency of barriers reported for women and girls (in order) as follows: social disapproval, prohibitive costs, perception of appropriateness, technical literacy, insufficient need, and lack of interest. Similarly, barriers to $3 \mathrm{G}$ access/the Internet can be ranked as prohibitive cost, low network quality, lack of interest, social disapproval, and insufficient need.

\section{Prohibitive cost}

Device ownership and access are markedly impacted by gender. As one example, interviews with Syrian refugees found females less likely to have reasonable access to phones. "In the family groups being interviewed, often-though not always-the men were the ones with 
the phone tucked into their pockets and not their wives, mothers, or daughters" (Wall et al. 2015). There are many factors influencing women and girls' mobile technology use. Affordability is a common challenge, worsened for females (Intel 2012). For households with few resources or an unstable income, the purchase of a mobile device, credit, and accompanying fees for ownership may limit the household to one device for the entire household or to a device only accessible by borrowing from a community member (Santosham 2015). Phone ownership is not prioritized for women and girls.

Survey respondents ranked the cost of the phone as the single greatest barrier to use for women and girls. This trend is consistent even considering age disaggregation. It follows in line with the earlier trend about phone sharing or borrowing. Users cannot access the full benefits of ICTs without device ownership. Understanding that in humanitarian contexts devices are typically borrowed is a crucial component for safety planning in implementation.

\section{Restrictive social norms}

Social disapproval is a unique barrier for women and girls. Global studies show low levels of acceptance influence use for women and girls. Even developing countries with more access to resources struggle to overcome this barrier. A 2012 study showed "one in five women in India and Egypt believe the Internet is not 'appropriate' for them" (Intel 2012). Perceptions of social prohibitions range from internalized norms to family or community restrictions (Intel 2012). Support, or the lack of support, from family or community members has a significant impact as a preventive action or as a great enabler.

As reported by all survey respondents regardless of age disaggregation, disapproval from family/friends, disapproval from community, and fear of harassment all appeared in the top five ranking for barriers to use. Prohibition or condemnation by family members or the community was reported as a strong influencing factor restricting use or desire to use. A majority mentioned the community disapproved of women and girls' use or had no opinion. In addition, women and girls expressed that in the community, there is always "fear for the protection of women and girls," which contributes to the lack of positive social norms around mobile technology use by females. Several examples were shared by women and girls about harassment through WhatsApp or by phone.

The impact of unequal gender social norms is underlying all the barriers reported. For example, the cost of devices, credit, or acquisition of SIM cards impacts both men and women. However, when women have less income because of fewer educational opportunities, increased likelihood to be married early, and less access to public spheres, cost- related barriers imply multiple additional gendered barriers to overcome for women (Santosham 2015).

Restricting social norms limits women and girls' full access to mobile phones. According to respondents, beyond sharing and borrowing, devices are also monitored or phone actions reviewed by parents, intimate partners, and in-laws. Nearly $20 \%$ of respondents reported that someone determined what they could or could not do on a phone. Twenty-two percent monitored what was done on the phone, including looking at WhatsApp history, looking at the screen while in use, reviewing the phone log, and browsing SMS history. Research in development contexts suggests that control of devices and access was perceived as needed by intimate partners and family members because ICTs are perceived as a channel to "pursue romantic liaisons outside of marriage, thereby threatening traditional social norms" (Santosham 2015). This sentiment was reflected as well by respondents and casework staff.

Respondents, who used phones themselves, had a higher perception of community approval of women and girls' use of phones and the Internet. Nearly half of this group believes the community approves of women and girls' use of ICTs. Comparatively, of the respondents who were not phone users, a majority perceived that the community would disapprove of women and girls' use of phones and the Internet.

\section{Low technical literacy}

Technical literacy also dilutes uptake for women and girls. Though not ranked by respondents as a barrier to use, when asked about increased phone use desire, only $4 \%$ cited lack of familiarity as the reason. When disaggregated, only $2 \%$ of adolescent girls (15-17) reported this as the reason, whereas $20 \%$ of ages $18-24$ reported this lack of literacy as the reason for reduced desire.

Low technical literacy reflects disparities in "in education, employment, and income [as women] lack the exposure to the Internet necessary for digital and information literacy, as well as opportunities to learn and practice computer skills" (Intel 2012). This relates back to social norms about women's roles in society and acceptable activities. Exposure to phones and the Internet typically occurs in public spaces such as school or work (Intel 2012). In developing countries and humanitarian settings where girls are restricted from participating in these spheres, it impacts their uptake of mobile technology. For women, who typically receive fewer educational opportunities, fewer opportunities to access technology, and overall, more basic handsets, technical confidence can represent a significant challenge and requires more significant investment and support to overcome (Santosham 2015). 


\section{Recommendations}

In considering ICT solutions, below are the recommended actions from assessment to implementation. These recommendations are supplementary actions to accommodate women and girls' unique risks and barriered access. These should be implemented in addition to basic ICT design principles. For adequate utilization, service providers should include safety planning around real and perceived risks of gender-based violence induced by technology adoption.

Given the safety concerns, service providers may opt to avoid mobile technology or only focus on coded or hidden language for activities. However, ICT is also a powerful means to advance gender equality and empowerment. Women and girls continue to bear the effect of global poverty, with lower education levels, less access to healthcare and other services, reduced asset ownership, gendered pay reductions, and mobility restrictions. Lessening the digital divide is one contribution toward changing these outcomes. It is essential for service providers to ensure women and girls have safe access to ICTs rather than avoid mobile technology altogether. ICTs can be used in a safe way focusing on women and girls' needs and ICT access rather than perpetrating violence against them by denying them access or deciding on their behalf to adopt coded or hidden language. ICT increases access of women and girls to critical information (whether medical or social and, here especially, safety).

Without access to ICTs, women and girls lose the opportunity of having their voices heard especially on online platforms, as ICT promotes personal development and makes women feel safer and empowered. We should listen to women and girls and to what they have to say about what they think is safe access to ICT and design ICT-facilitated programs based on their feedback rather than designing ICT tools and sharing them with communities without first considering safe access measures.

\section{Assessing for risk Consider trends in gender-based violence}

Globally, the estimate is that one in three women has experienced physical or sexual violence (World Health Organization 2013). In conflict settings, threats to women's safety are more acute as crisis and forced displacement further dilute protections women can access, and genderbased violence intensifies (International Rescue Committee 2013)

In many humanitarian settings, women report intimate partner violence and other forms of gender-based violence, overcrowded living conditions with lack of privacy, compromised safety, and a reluctance to report violence and receive services (Anani 2013). Stigma, shame, and fear of retribution reduce help-seeking behaviors. This is exacerbated by information precarity, "a condition of information instability and insecurity that may result in heightened exposure to violence" (Wall et al. 2015).

Given that violence escalates in humanitarian settings, it is crucial for recommended ICT implementations to consider women and girls' real and perceived risks, and apply the necessary safety planning before introducing technology that could increase risks of harm. An initial assessment of available data on reported trends will aid in understanding the context of gender-based violence in the setting.

\section{Conduct participatory assessments}

Consultations and focus group discussions with different groups of women and girls are a requirement prior to the introduction of any ICT solution to avoid causing unintentional harm. Prior to participatory assessments, it is crucial for service providers to prioritize the safety of women and girls while conducting these assessments. This requires building trust with affected communities in general and women and girls specifically. This can be done through ongoing introductory visits to the community and non-focused PSS needs assessments to make sure the trust process is progressing. In addition, service providers should ask women and girls to identify a space where they feel safe to participate in the assessment, appropriate timing, safe setting, and any needed mitigation strategies if freedom of movement is restricted. This should be conducted prior to the ICT assessment.

After considering safety concerns and trust-building, participatory assessments should include community mapping for safety concerns. These safety concerns can provide information about power dynamics that could affect safe mobile use. For example, information about high rates of intimate partner violence combined with trends in device sharing should trigger a consideration of harm reduction techniques.

Service providers could also conduct a digital safety mapping. In this, women and girls would develop a visual representation of how they currently use mobile phones/the Internet, how they would like to use it, and their safety concerns. These activities will allow service providers to understand risks and ways to mitigate them.

Focus group discussions can also be used to propose solutions and gather feedback from women and girls. For example, with an information awareness campaign that shared news about service availabilities, service providers could gather feedback about the specific information desired; the timing of the message, if the message should be disguised with other information; the preferred channel (e.g., WhatsApp); and any safety concerns.

These assessments can include a series of questions about general population mobile technology usage, 
personal usage and access, real and perceived safety risks, and desired uses. To get more in-depth information, this could include vignettes that provide participants with a clear case study to formulate an opinion.

\section{Plan for safe use}

Based on survey responses, there are several important trends to consider for the deployment of mobile/Internetbased interventions or communication methods with displaced women and girls. Most often shared or borrowed phones are owned by parents or intimate partners. If service providers are considering ICT channels for engagement with female beneficiaries, this has a significant impact on the types of services that can be safely offered and safe communication methods via mobile or the Internet. For example, in considering phone-based services, service providers can and should ask women and girls about the way that they would like to receive the service. The service provider should ask the women and/or girls about the time that she would like to have a call, e.g., if she prefers to call rather than receiving a call or if she would prefer to send a missed call to the service provider when she feels safe. Further, applications that facilitate a user accessing online GBV counseling need to be weighed against the likelihood of an intimate partner accessing this information, which could result in an increased risk of harm.

In addition to the lack of phone ownership, phone use should be considered monitored and subject to approval. One third of respondents in the survey had their phone use monitored. This, too, has an impact on the ability for safe service provision and communication for potential survivors of family or in-home violence. Phone monitoring takes the form of looking at the screen during use or reviewing chat and phone logs. This means any ICT solutions would benefit from understanding who is viewing the content (the language of the message, the timing of the message, and the sender name). Expectations can be made from this survey that users in settings like those in the humanitarian sites in Lebanon have reasonable, near-daily access, but that what they do could be monitored. Engagement channels should not bring additional harm to users.

Safety precautions should be built into all ICT solutions with women and girls. This means consulting women and girls in advance of deploying an ICT intervention to assess unique safety risks and feasibility. This client-responsive design style is highly recommended to ensure additional harm is not introduced and that ICT tools or platforms are utilized in the manner intended. Assuming mobile devices are shared or borrowed should force implementers to consider wrapping, associating, or including sensitive content (e.g., gender-based violence response services) with other general information, for example having a website or Facebook page that highlights women's health services and, as can be also discussed in a masked manner, intimate partner violence. Implementers could also consider ICT tools that can accommodate a "quick escape" button so the user can quickly leave the site if someone starts to monitor their use. Planning could also include safety tips on technical literacy and how to be safe on the Internet.

A good example of planned safety measures in ICTs is the myPlan application. This application has users create a $\log$-in to access safety planning. Immediately after login, users are directed to create a PIN and informed that if someone is with them and reviewing what they do, they can enter a PIN of 0000 to immediately view nonthreatening content and not expose their responses. Products that program around this assumption of multiple users "could help female borrowers move more quickly up the digital ladder and reap the benefits of more active mobile usage" (Santosham 2015).

Community sensitization could be a crucial activity to raise community member awareness about the purpose and content of any new ICT tool. This can help to prevent rumors or rejection of the tool's implementation and help to build confidence in the tool's purpose. It is recommended that service providers reach the whole community, including women, men, girls, and boys by tailoring key messages about the new ICT tool. It is also important to validate the key messages by women and girls from the same community to make sure that key messages are relevant to the context and respect the accepted norms of the community.

It is crucial for service providers to engage with men and boys and to build trust with them in order to start the shift in thinking and to gain them as allies in the process. This can include disseminating key messages on ICTs with men through information sessions or through reflective discussions to start the process of changing perceptions of ICT use. In parallel, the same types of activities also need to be conducted with women and girls as they are influenced by the gender norms and community acceptance to ICT access and use. Ask women and girls what they think is appropriate to be shared with the male social network (whether father, husband, uncle, father in law, etc.) and to design the key messages with them and to take their consent before reaching out to men and sharing these key messages with them.

\section{Raise awareness about technology abuse}

Prior to implementing ICT tools as part of or to promote an intervention, staff and potential users need to be aware of technology abuse, electronic sexual coercion, and safe use. As community sensitization focuses on preventing misunderstandings about the purpose of the ICT tools, guidance to users on technology abuse can prevent victimization. 
Technology abuse is the misuse of technology by perpetrators, which could include stalking, tracking, harassing, and monitoring. Assessing for technology abuse should be built into assessments of safety in discussions with survivors and embedded as part of the safety planning process. Casework staff can ask about safety concerns as it relates to technology, identify the types of technology (applications, websites, social media, or other communication channels) used by the perpetrator, and assess what the survivor understands about the abuse. The National Network to End Domestic Violence suggests asking questions about tracking of the survivor by the perpetrator, perpetrator's access to the survivors' communication with other people, information posted in online settings, and maintaining safety and privacy while using technology (Technology Safety 2014a).

Electronic sexual coercion (ESC) is coercive sexting. This includes sending unwanted sexual photos, pressuring to send sexual photos, sharing sexual photos without permission, and pressuring to meet in person with the intent of sexual activity. This is also called genderbased cyber violence. Staff should help inform women and girls about the signs of ESC, steps to avoid, and safety planning. In some settings, documenting ESC can be helpful to survivors. Documentation may aid in building an evidence base for legal action, if these laws are applicable in the setting. Documentation may also help identify patterns in technology abuse and points of escalation.

Safety planning can be used for technology as well. The first step in technology safety planning is to identify the misused technology by the perpetrator. This will aid in creating a customized safety plan for the survivor. There are a range of activities women and girls can take to better protect their device, data, and privacy in digital settings. This can include using a different, safe device; changing passwords; turning off location-tracking settings on mobile devices; obtaining new devices; limiting public information shared on social media sites; and documenting any incident of technology abuse or electronic sexual coercion.

There are likely to be challenges in training women and girls on these protective measures. Low literacy levels and lack of device ownership constitute some of the main challenges as women and girls on do not have regular access. This impacts their ability to retain information and increases the risk of forgetting the information due to lack of practice. To overcome this barrier, service providers should focus on spaced learning (meaning learning over time in small amounts) and retrieval practice so the action is memorized over time instead of having to rely on a resource or person for instruction. Most importantly, ongoing followup should be a structured part of any ICT tool to ensure protective measures are updated and adjusted as needed.

\section{Design}

Design principles should be contextualized according to gender. This includes mainstreaming considerations for violence risks, access, barriers to use, and technical literacy. Primarily, this means managing risk. From the perspective of the end user, consider safety concerns, device ownership and access, and the level of risk involved. ICTs should follow the principle of do no harm. This should also include data protection considerations. Adhere to international and national standards for data protection. If data is collected from the user, consider the risks if this information was exposed. If personal information is collected from the end user or about displaced populations, informed consent must be provided in advance of data collection, citing the purpose for data gathering.

\section{Adapt for the context}

Similar to any project design, it is essential to understand the setting and adapt products developed to match the context and particular access issues, including language, levels of literacy, education, discrimination, freedom of movement and isolation, and other sociocultural norms. For settings with low literacy, service providers can introduce technology literacy sessions or introduce audiobased or visual applications to accommodate users. This can include trainings and capacity building in safe spaces (static or mobile) after first consulting women and girls for their interest and consent for this type of activity.

In addition to a full assessment of risks, it is crucial to also allow enough time for women and girls to absorb new technology. This includes a thorough user acceptance testing process and discussions about security of data and security of device use.

When introducing ICT tools, in all contexts, obstacles, barriers, and interest of women and girls in accessing and using technology should be prioritized and should guide any intervention approach. Barriers can be common; however, their severity can vary from one context to another. For example, in some contexts, device costs are prohibitive and the primary barrier to use. In other contexts, devices may be obtained, but low literacy levels prevent their safe and effective use. The crucial component is to put women and girls at the center of the intervention; listening to women and girls, their needs, opinions, preferences, interest, and obstacles is essential for every tailored intervention with women and girls rather than assuming that humanitarian actors know their needs.

Integrating ICTs within GBV programming can inform programming and facilitate the access of the most vulnerable women and girls to information and resources. ICTs can be integrated into the needs assessments that usually identify focused and non-focused psychosocial needs. If women and girls do not identify technology 
literacy, the service provider can share that this is an option to be included in the safe space activities and open the space for women and girls to decide whether they would like to have these sessions or not. After several weeks of non-focused psychosocial sessions (to build trust), service providers can call for an advanced ICT assessment where they assess the actual access of women and girls to technology, pace, needs, interests, safe ways of using technology, associated risks of violence using technology, previous good experiences using technology, and new ICT tools to explore. As a regular practice, service providers can also integrate questions on ICT risks and cyber violence in GBV risk assessments.

\section{Know the wireless broadband network coverage and quality}

Technical requirements must meet network coverage and device model ownership, or service providers must resolve these barriers through the introduction of remote Wi-Fi hotspots or device and credit distribution. For example, in Lebanon, 3G Internet is unreliable in border areas, so disseminating information over Internet-based platforms would not be inclusive of these population groups as compared to those in more urban areas such as Beirut. In the former settings, gaps in wireless networks would have to be assessed and the challenge addressed.

When considering offering devices or credit, the same risk mitigation strategies should be considered as with material or cash assistance, which can potentially heighten women and girls' vulnerability to violence as a result of benefiting from the acquisition. Distribution should be explored on a case-by-case basis. Or alternatively, offering access to $\mathrm{Wi}-\mathrm{Fi}$ in safe spaces when available and ensuring women and girls have the basic skills to use phones and access the Internet should be considered. In advance of this type of implementation, it is crucial to conduct participatory assessments with women and girls and monitor usage for increased risks.

\section{Available and preferred platforms and usage}

Targeting the introduction of ICTs toward channels that the target population is already familiar with will aid in uptake. High familiarity and preference for texting-based apps such as WhatsApp or Skype are examples of highly preferred platforms. For this, it is crucial to have discussions and consultations with women and girls about their access to phones and preferred content or communication channels.

\section{ICT solutions for the GBV sector, GBV survivors, and safe spaces}

ICT opportunities for service providers in the gender-based violence sector

In sites where engagement with female beneficiaries is deemed too risky, organizations can still use ICTs with their staff. Even with the most conservative outlook on safety in ICT deployment, mobile technology can still be utilized for casework staff engagement, continued skill building, and assessment. This can take the form of access to content through mobile applications such as a pocket guide to psychological first aid or guidelines on mainstreaming or communication or attitude skills. This can be a useful resource, consumable offline, and convenient to access when needed. There may be increased likelihood of guidance uptake if it is easy to access and written and formatted in an easy-to-find fashion.

\section{Mobile data collection in case management}

Safely and ethically managing case and incident records is a core part of work in the field of protection or gender-based violence response programming. Adequate and appropriate data storage ensures due diligence in the responsibility to the survivor to protect their confidentiality. Because of security concerns, lack of adequate storage options, or a desire to be more environmentally conscious, many programs may be considering a shift to paperless programming. This requires the proper allocation of resources, commitment for the continual use of mobile data collection, sustainable resources, and continuous assessment of adequate data collection and data storage.

The desire to reduce paper in the case management process has many benefits. For instance, it lessens the need for storage and physical protection of file cabinets freeing up office space and makes case files more readily reviewable by supervisors, especially in a remote management or mobile service delivery settings. Paper-light or paperless offices can also improve problems with loss or misplacement of physical paper records, reduce time spent handling paper records, facilitate the sharing of data, improve data quality through facilitated review, and ease retrieval of needed information.

However, these benefits need to be weighed against perceptions of confidentiality and the survivor-centered approach to care. Respondents had mixed levels of comfort about speaking to a caseworker who is using a tablet during a case management meeting for data collection. Less than half would approve of this outright, nearly half would approve if the caseworker explained the use of the device, and $19 \%$ would disapprove even if explained. For the latter, respondents provided feedback that their experience of comfort in speaking with the caseworker would lessen with the device being a barrier to the dynamics of their relationship. Additionally, a lack of understanding and confidence of what is being documented (even if explained) affected their level of comfort with mobile devices being present. Most respondents who answered positively to this question added that they would approve because they know the caseworker and 
trust them. This highlights the need for strong and solid trust with communities before considering the use of mobile technology for data collection with survivors of gender-based violence.

For other forms of service provision unrelated to case management or reports of gender-based violence, there is likely a higher acceptance rate for the presence of mobile technology for data collection. However, given the setting of the survey, in the women's center, the understanding of case management was likely associated with reporting gender-based violence, a highly sensitive topic with higher standards for privacy, confidentiality, and higher risks for data loss or unauthorized access.

\section{ICT opportunities and resources for survivors of gender- based violence}

Phones and other mobile devices represent an opportunity for service providers to connect with beneficiaries to increase their access to information and offer resources and assistance. However, device usage and the information stored on devices come with risks to safety and privacy. This needs to be the central element of consideration before developing or implementing any ICT tool with women and girls. In addition, the name of the organization and the information should be accurate and informative. Often, women and girls can receive wrong information from fake accounts.

ICT tools can be used in programming with women and girls for a variety of purposes. If an application or website is targeting female survivors of gender-based violence, they can offer information or awareness raising, screening tools, or safety aids. Before implementation, it is important to consider, through consultation with women and girls in the setting, if potential or actual perpetrators have access to the device (which can be assumed), if they are monitoring activity, if the name or icon or external information about the application or website displays any information that could be harmful (e.g., GBV survivor app would be harmful), if the application asks for identifying information or location sharing, or if the communication methods offered are safe (Technology Safety 2014b). Because screening applications likely ask about details of the violence, it is important that this information is non-identifying, protected, not externally or easily known content, and easily removable. After screening, follow-up with women and girls is essential to make sure they have ongoing safe access to smart phones and Internet, as the perpetrator can start accessing devices halfway through the use, for instance.

Applications or other ICT tools can also be used for safety purposes. This could include safety decision aids or emergency communication. With these aids, it is crucial to consider perpetrator monitoring, thorough testing of the product or tool, and to continue to promote in-person assistance. Applications and ICT tools can assist with the process but should not be used in place of counseling assistance available in-person or remotely as they cannot compensate for the human factor in face-to-face counseling. I-Decide is one example of a safety aid tool that has a quick escape "exit" button that takes the person to a weather page, if they think someone is monitoring their use. However, considering Internet speed and challenges, it is more challenging to have this kind of app and adaptation function appropriately in humanitarian settings. Testing is, therefore, essential.

\section{Wi-Fi access, library phones, or information stewards}

To promote usage and access to phones and the Internet, one option to overcome the barrier or prohibitive cost for device or credit is by providing temporary or limited access to phones and the Internet. This can be done through two models that each warrants further investigation. One option is to provide a $\mathrm{Wi}$-Fi-enabled safe setting. In this model, an organization provides free Wi-Fi access for beneficiaries who bring their own device. This would likely be a draw for beneficiaries and would need to be balanced against community assumptions about activity that could introduce additional harm to women and girls.

A second option is a library or "checking out" model or through information stewards that provide devices with connectivity for a limited time period or while in the provider office. Alternatively, community mobilizers or focal points could be deployed to safe spaces or safe community gathering locations to distribute reliable information and safe spaces or service options (di Giovanni 2013).

In addition, and to promote usage and access to phones and the Internet, technology literacy sessions can be conducted in the safe spaces where women and girls are equipped with skills to use phones in a comfortable way. It is of importance to ask women and girls if this is something they are interested in, they would like to do, and that they feel safe doing.

Assumptions about how phones or the Internet will be accessed that could create additional harm. For instance, community members who perceive that access to Wi-Fi or library phones is checked out to facilitate conversations between women and girls and male community members for romantic purposes could put beneficiaries or staff in additional harm. An assessment before implementing this service would need to be conducted as well as consistent messaging to the community on the purpose and scope of Wi-Fi access 
and the use of library phones or information stewards throughout implementation. For this model to function and avoid increasing the potential for harm, focus group and community discussions with women and girls should inform the decision to implement and the approach for implementation, utilizing the assessment to determine interest, readiness, and risk factors.

\section{Conclusion}

Information and communications technology has potential in humanitarian settings to broaden access to information, aid in service provision and safety planning, and facilitate data collection. However, enthusiasm for the introduction of technology needs to be well balanced against the real and perceived harmful effects of technology for women and girls.

Findings from the survey revealed similar trends in humanitarian settings to those in development settings in terms of access and usage. There is a gendered imbalance for women and girls. Heightened in humanitarian settings, there is also a greater need to assess and plan around safety and privacy issues for women and girls using shared or borrowed devices. Service precautions in planning the introduction of ICTs are required. Implementation should only begin after consultations with women and girls in each setting as threats and risks of use will be unique. The results in Lebanon, however, do provide general guidance on key considerations for planning, designing, and implementing ICT tools for service use.

\section{Endnotes}

${ }^{1}$ Gender Based Violence Information Management System Lebanon (2018) data. Note: These statistical trends are generated exclusively by gender-based violence (GBV) service providers who use the GenderBased Violence Information Management System (GBVIMS) for data collection in the implementation of GBV response activities across Lebanon and with the informed consent of survivors. Eight organizations contributed to these trends. This data cannot be used for any individual follow-up.

\section{Abbreviations}

ESC: Electronic sexual coercion; GBV: Gender-based violence; ICT: Information and communications technology; IRC: International Rescue Committee; PSS: Psychosocial

\section{Acknowledgements}

The authors would like to acknowledge each participant for the time and effort provided. The authors would like to also acknowledge the contributions of casework staff from ABAAD, Danish Refugee Council, International Rescue Committee, INTERSOS, and Caritas in the data collection. The authors would like to acknowledge Sunita Palekar Joergensen for contributions in the drafting of the survey.

\section{Funding}

The research was funded internally by the International Rescue Committee $\mathrm{HQ}$ and the Lebanon country office. Enumeration support came from the International Rescue Committee Lebanon, ABAAD, Danish Refugee Council, INTERSOS, and Caritas.

Availability of data and materials

Data is available upon request from the authors.

\section{Authors' contributions}

KC completed the literature review, drafted the survey, performed the analysis, and drafted the manuscript. PG participated in coordinating the translation of the survey, drafting the survey, recruiting enumerators, provided the translation for survey responses, and assisted in the data interpretation. Both authors read and approved the final manuscript.

\section{Authors' information \\ Kristy Crabtree is the Gender-Based Violence Information Management Spe- cialist in the International Rescue Committee's Violence Prevention and Re- sponse unit. She is part of the inter-agency Gender-Based Violence Information Management System Steering Committee. \\ Petronille Geara is the Women's Protection and Empowerment Coordinator in the International Rescue Committee's Lebanon office.}

\section{Ethics approval and consent to participate}

International Rescue Committee Institutional Review Board approval was obtained in March 2017. Respondents' consent was ensured, though no names or other identifying information were collected.

\section{Competing interests}

The authors declare that they have no competing interests.

\section{Publisher's Note}

Springer Nature remains neutral with regard to jurisdictional claims in published maps and institutional affiliations.

\section{Author details}

${ }^{1}$ International Rescue Committee, 122 E. 42nd Street, New York, NY 10186, USA. ${ }^{2}$ International Rescue Committee, Beirut, Lebanon. ${ }^{3}$ Seattle, USA.

Received: 1 December 2017 Accepted: 19 February 2018

Published online: 09 March 2018

\section{References}

Anani G (2013) Dimensions of gender-based violence against Syrian refugees in Lebanon. Forced Migration Review 44:75

di Giovanni (2013) Lost: Syrian refugees and the information gap. In: Internews, Available via https://www.internews.org/sites/default/files/ resources/Internews_Lost_SyriaReport_Nov2013_web.pdf. Accessed 16 Nov 2016

Intel (2012) Women and the web: bridging the Internet gap and creating new global opportunities in low and middle-income countries. In: Intel. Available via https://www.intel.com/content/dam/www/public/us/en/documents/pdf/ women-and-the-web.pdf. Accessed 16 Nov 2016

International Rescue Committee (2013) Life saving not optional. In: International Rescue Committee. Available via http://themimu.info/sites/themimu.info/ files/documents/Ref_Doc_Lifesaving_Not_Optional_-_Discussion_Paper_ Feb2013.pdf. Accessed 20 Oct 2016

Santosham, Lindsey (2015) Bridging the gender gap: mobile access and usage in low and middle-income countries. In: Connected Women. GSMA. Available via https:/www.gsma.com/mobilefordevelopment/wp-content/uploads/2016/02/ Connected-Women-Gender-Gap.pdf. Accessed 16 Nov 2016

Technology Safety (2014a) Assessing for technology abuse and privacy concerns In: Technology Safety. National Network to End Domestic Violence. Available via https://www.techsafety.org/resources-agencyuse/assessing-tech-abuse/. Accessed 1 Feb 2017

Technology Safety (2014b) Choosing and using apps: considerations for survivors In: Technology Safety. National Network to End Domestic Violence. Available via www.techsafety.org/choosingapps. Accessed 1 Feb 2017

Wall M, Campbell M, Janbek D (2015) Syrian refugees and information precarity. New Media Soc 19(2):240-254 
World Health Organization (2007) WHO ethical and safety recommendations for researching, documenting and monitoring sexual violence in emergencies. In: World Health Organization. Available via http://www.who.int/gender/ documents/OMS Ethics\&Safety10Aug07.pdf. Accessed 10 Dec 2012

World Health Organization (2013) World Health Organization, Department of Reproductive Health and Research, London School of Hygiene and Tropical Medicine, South African Medical Research Council (2013)

\section{Submit your manuscript to a SpringerOpen ${ }^{\bullet}$ journal and benefit from:}

- Convenient online submission

Rigorous peer review

- Open access: articles freely available online

- High visibility within the field

- Retaining the copyright to your article

Submit your next manuscript at $\gg$ springeropen.com 